\title{
Elementos para uma filosofia universal da biologia: vida e a origem da ordem
}

Elements for a universal philosophy of biology: life and the origin of order

\author{
Letícia Paola ALABI ${ }^{1}$ \\ Charles Morphy D. SANTOS²
}

\section{Resumo}

O Darwinismo Universal foi um conceito desenvolvido por Richard Dawkins em 1983. Ele responde positivamente à conjectura "Se existe vida fora da Terra, os organismos evoluem como os seres vivos da Terra?". Por implicar em uma pergunta empírica, testável apenas quando encontrarmos vida extraterrestre, ela pode ser reformulada nos seguintes termos: "se existe vida fora da Terra, conseguiríamos detectá-la utilizando ferramentas baseadas no Darwinismo Universal?". Cabe avaliar se a complexidade adaptativa centrada na seleção natural seria suficiente para explicar a evolução orgânica em qualquer parte do universo. O próprio Charles Darwin defendia um pluralismo explicativo para a evolução. Aqui, a proposta é discutir uma definição geral de vida não fundamentada exclusivamente na ideia de seleção natural mas incluindo conceitos como a autoorganização, que explica a emergência da ordem biológica a partir de características intrínsecas dos sistemas físico-químicos. O darwinismo estendido é um possível quadro teórico que busca uma compreensão universal da vida como um fenômeno emergente no intuito de reabilitar a universalidade e autonomia biológica, tendo como norte diferentes mecanismos evolutivos. Assim, abre-se um novo nicho epistemológico, que permite desenvolver uma visão plural para a filosofia da biologia.

Palavras-chave: auto-organização; bioassinatura; Darwinismo Universal; seleção natural; vida.

\section{Abstract}

Universal Darwinism was a concept developed by Richard Dawkins in 1983. It responds positively to the conjecture "If there is life beyond Earth, the organisms evolve as living beings on Earth?". Since it implies an empirical question, testable only when we find extraterrestrial life, the question can be reformulated as follows: "if there is life beyond Earth, we could detect it using tools based on Universal Darwinism?". We should evaluate if adaptive complexity focused on natural selection would be sufficient to explain the organic evolution in the whole universe. Charles Darwin himself advocated an explanatory pluralism to evolution. Herein, the proposal is to discuss a general definition of life not exclusively based on the idea of natural selection, but also including concepts such as selforganization, which explains the emergence of biological order from the intrinsic characteristics of the physical-chemical systems. The extended Darwinism is a possible theoretical framework that seeks a universal understanding of life as an emerging phenomenon in order to rehabilitate the universality and autonomy of biology based on different evolutionary mechanisms. Thus, a new epistemological niche is opened, which allows the development of a pluralistic vision for the philosophy of biology.

Keywords: self-organization; biosignature; Universal Darwinism; natural selection; life.

\footnotetext{
${ }^{1}$ Universidade Federal do ABC (UFABC) e Universidade do País Basco (UPV/EHU)

${ }^{2}$ Universidade Federal do ABC (UFABC)
} 


\section{Introdução}

É quase unanimidade nas ciências naturais dizer que a física e a química são universais. A biologia fica excluída desse rol de disciplinas. No entanto, para se compreender a origem dos seres vivos e como podemos reconhecê-los universo afora, é importante que se determine o grau de universalidade da biologia, o que demanda uma definição não ambígua de vida.

Definições nem sempre são simples. Para a maioria, elas são apenas formas de organizar conceitos. Segundo o Oxford Advanced Learners Dictionary, uma definição é "uma explicação do significado de uma palavra ou frase; o que uma ideia significa". Ela especifica as condições necessárias e suficientes para a aplicação do termo ao qual se refere. Com o termo "vida", isso torna-se mais complicado pois defini-lo não é apenas uma questão de amarrar uma coleção de conceitos de disciplinas diferentes (Emmeche \& ElHani, 2000).

Atualmente, considera-se vivo o que apresenta certas propriedades gerais - ao menos segundo o tipo de organismos que conhecemos. A partir disso as definições são variadas (Luisi, 1998; Benner, 2010). Por exemplo:

- Vida é tudo aquilo com capacidade de auto-reprodução, armazenamento de informação para sua auto-representação, metabolismo, interações funcionais com o ambiente em seu entorno, interdependência de suas partes constituintes, estabilidade sob perturbações e habilidade de evoluir;

- Vida é aquilo com metabolismo, auto-reprodução e possibilidade de sofrer mutações;

- Vida é aquilo com comportamento finalista, morfogênese autônoma e invariância reprodutiva;

- Vida é um conjunto de sistemas complexos e adaptativos com um caráter intrínseco de historicidade, uma vez que as classes de organismos seriam definidas por suas conexões históricas de ancestralidade-descendência resultantes do processo de seleção natural.

Por mais acertadas que pareçam cada uma dessas definições, elas não chegam ao cerne do problema. Como argumentam Cleland \& Chyba (2002), o que se procura não é o que a palavra vida significa para nós e sim o que é vida de fato. Eles trabalham a partir da ideia de tipos naturais, que são aqueles definidos pela natureza e não por convenções humanas. Termos que designam tipos não-naturais, em contrapartida, baseiam-se nas propriedades usadas para reconhecê-los e não tem uma natureza independente delas. Água seria um exemplo de tipo-natural. Quando compreendemos a natureza molecular da água, conseguimos identificá-la sem ambiguidades: água é H2O. Antes de os cientistas terem descoberto essa natureza, a água era identificada apenas por suas características superficiais: "um líquido incolor, inodoro, transparente". Na biologia, os esforços devem ser direcionados para uma teoria que permita entender a natureza da vida e formular uma identidade precisa para ela comparável à afirmação "água é $\mathrm{H} 2 \mathrm{O}$ ".

Uma pergunta central para essa busca, que deriva de grande parte das definições citadas acima, é "Se existe vida extraterrestre, tais organismos evoluem como os da Terra?". O que se quer saber é se a complexidade adaptativa centrada na evolução darwiniana por seleção natural seria por si só, aqui ou em qualquer parte do universo, suficiente para explicar toda a evolução orgânica. O próprio Darwin (1859), no seu On the origin of species, 
defendia um pluralismo explicativo para evolução, a despeito de centrar seu longo argumento na ideia de reprodução diferencial a partir da seleção natural de variedades préexistentes.

Este ensaio discute se uma definição geral de vida pode estar fundamentada na ideia de seleção natural ou se é necessário rediscutir o Darwinismo Universal à luz de conceitos tais como a auto-organização, que podem explicar a origem da ordem biológica a partir de características intrínsecas dos sistemas físico-químicos. Pela falta de uma definição mais ampla, a detecção de bioassinaturas - atributos químicos, físicos ou fisiológicos que denotam a presença de organismos - torna-se limitada por se restringir apenas aquilo que, independentemente do lugar que ocupa no universo, passa por um processo de seleção natural. A expansão do conceito de Darwinismo Universal à luz da auto-organização servirá como arcabouço para uma filosofia universal da biologia, apta a abarcar a origem da ordem biológica na Terra e a determinar diretrizes para a busca de vida fora do nosso planeta. Aqui, o conjunto de hipóteses e teorias intitulado darwinismo estendido funcionará como um possível quadro teórico para se chegar a uma compreensão universal da vida como um fenômeno emergente, levando em conta seus procedimentos metodológicos, suas peculiaridades explicativas e seus problemas conceituais.

\section{Darwinismo universal e auto-organização}

Desde o trabalho de Darwin (1859), muitos têm tentado aplicar a teoria da evolução a outros fenômenos naturais e sociais fora do espectro biológico propriamente dito. De estrelas e galáxias, passando por economia, sociologia, antropologia e física das partículas elementares, é fácil encontrar os termos darwinismo e evolução fora de periódicos e livros dedicados às ciências biológicas. No entanto, o Darwinismo Universal, como discutido por Dawkins (1983), nada tem a ver com a "evolução" de galáxias ou sistemas econômicos. Sua universalidade não significa que ele pode ser usado para compreender todo tipo de processo ou sistema que mude com o tempo. O que Dawkins defende é que qualquer forma de vida existente no universo sofre pressões seletivas e mudanças na sua constituição genética. Tais variações pré-existentes seriam fundamentais para a possibilidade de reprodução diferencial, isto é, seleção natural.

O Darwinismo Universal influencia muitas das definições de vida. Darling (2007) argumenta que é altamente concebível que toda a vida no universo tenha evoluído por algo semelhante ao darwinismo, pois as noções de seleção natural e replicação seriam específicas para entidades biológicas, o que permitiria uma definição simples e geral capaz de cristalizar todas as ideias existentes sobre os mecanismos que originam sistemas vivos em uma perspectiva evolutiva. Na opinião de Dawkins (1983), à presença de complexidade adaptativa em uma forma de vida deve corresponder a existência de um mecanismo seletivo capaz de gerá-la. Para Dawkins, a generalização que pode ser feita sobre a vida no universo é que ela será sempre reconhecida como vida darwiniana.

Muitos discordam desse ponto-de-vista, já que a vida em outros planetas pode ser distinta do que a concebida com base no referencial terrestre. Porém, o procedimento primário da pesquisa astrobiológica é extrapolar nossa biologia para o universo. Mesmo que outras biologias existam, por mais que estejam próximas, ainda não temos a competência para identificá-las. A não ser, obviamente, que estendamos nossos conceitos, para que sejamos capazes de desvendar formas alternativas de vida, presentes mesmo no nosso planeta, no que se convencionou chamar de "biosfera oculta" (Davies et al., 2009). A escolha 
que temos é caracterizar vida a partir das considerações darwinianas sobre a evolução, complementando-a com desenvolvimentos da teoria evolutiva alcançados nas últimas décadas. Nesse ínterim pode-se discutir a importância e ubiquidade da auto-organização.

Darwin (1859) não poderia ter suspeitado da existência da auto-organização, fenômeno descrito no século XX para explicar uma série de padrões globais que emergem em um sistema de maneira espontânea a partir de interações entre as suas subunidades, não havendo informação ou padrão imposto vindo do exterior (Kauffman, 1993, 2014; Depew \& Weber, 1995; Emmeche \& El-Hani, 2000; Ruiz-Mirazo et al, 2000). A autoorganização procura descrever a emergência de estruturas complexas e funcionais em sistemas dinâmicos. A forma esférica que assume uma gota de óleo em água, o padrão simétrico radial com seis eixos exibido por um floco de neve, o dobramento espontâneo de proteínas e a formação de membranas com bicamadas fosfolipídicas são exemplos de sistemas auto-organizados. Visto que a auto-organização atua em diferentes tipos de sistemas e níveis de organização biológica, Ruiz-Mirazo (2013) a define como um fenômeno dinâmico em que um grande número de unidades individuais, tais como moléculas, células e organismos multicelulares, espontaneamente gera uma correlação irredutível, um padrão coletivo de ordem ou comportamento envolvendo todas as unidades constituintes, que não pode ser compreendido a partir das propriedades individuais das mesmas.

A partir de fenômenos emergentes, como entender, em termos universais, um padrão geral, se ele de fato existir? Ironicamente, o organismo parece ter desaparecido das explicações (Ruiz-Mirazo, 2000; El-Hani, 2002). O que se busca é a proposição de uma forma geral de se compreender um sistema biológico a partir de suas regras próprias autônomas. Nesse sentido, o próprio espaço darwiniano dever ser repensado em termos sistêmicos. Aqui, defendemos que a autonomia do organismo (Ruiz-Mirazo, 2000; El-Hani, 2002) pode fornecer diretrizes e princípios mais gerais capazes de englobar qualquer tipo de vida.

Segundo Kauffman (1991, 1993), estamos apenas começando a compreender a evolução como a relação íntima entre seleção e auto-organização. Kauffman (1991) define o conceito de anticaos como sendo a propriedade de sistemas altamente desordenados se cristalizarem espontaneamente em um alto grau de ordenação. $O$ anticaos seria fundamental para a evolução, uma vez que a ordem biológica poderia refletir, ao menos em parte, esse ordenamento espontâneo dos sistemas que se auto-organizam, nos quais a seleção natural agiria.

Kauffman constrói parte do seu raciocínio a partir do conceito de redes Booleanas (Kauffman, 1991, 1993, 1995). Em uma rede desse tipo, cada variável é regulada por outras, em um sistema semelhante ao liga/desliga de um interruptor; o comportamento dinâmico de cada variável (se ela estará ligada ou desligada no momento seguinte) é controlado por uma função Booleana. O surgimento da vida dependeria da auto-ordenação de sistemas pré-bióticos semelhantes à redes Booleanas autônomas do tipo NK, que podem dar origem a conjuntos autocatalíticos. Constituídos por $\mathrm{N}$ elementos ligados por $\mathrm{K}$ entradas (ou interconexões) por elemento, corresponderiam a sistemas de moléculas que, em sua interação, atuariam como catalizadores de suas próprias reações. Tais sistemas pré-bióticos existiriam em três configurações básicas, "sólidas", "líquidas" e "gasosas". Redes altamente caóticas (gasosas) seriam tão desordenadas que impossibilitariam a manutenção e o controle de comportamentos complexos. Redes muito ordenadas (sólidas) estariam paralisadas demais para coordenarem tais tipos de comportamentos (um exemplo simples pode ser visto na Figura 1). Apenas nas redes "líquidas" uma dinâmica envolvendo coordenação complexa de atividades através da rede seria possível. A vida estaria, portanto, 
entre os estados sólidos e gasosos dessas redes Booleanas pré-bióticas (que muitos chamam de borda ou limite do caos). A margem do caos é o limite de coexistência entre a ordem e a desordem, que pode gerar novidades evolutivas. Os regimes ordenados que se aproximassem dessa margem seriam favorecidos pela seleção natural.

Kauffman parte da ideia de conjuntos autocatalíticos buscando encontrar quais requisitos garantiriam a autonomia de um sistema vivo. Para isso, ele utiliza a ideia de agentes autônomos (2003) e desenvolve um conceito de autonomia articulada com a termodinâmica (na qual a funcionalidade, as restrições do sistema e os ciclo de trabalho se definem mutuamente). Kauffman tenta explicar quais os requerimentos básicos da existência desses sistemas autocatalíticos. Compreender o surgimento de agentes autônomos na biosfera vai depender do desenvolvimento de uma teoria adequada capaz de explicar como processos bioquímicos são capazes de se auto-organizar. Kauffman (2001), nesse sentido, defende que a definição de agentes autônomos vivos são centrais na busca de uma biologia geral.
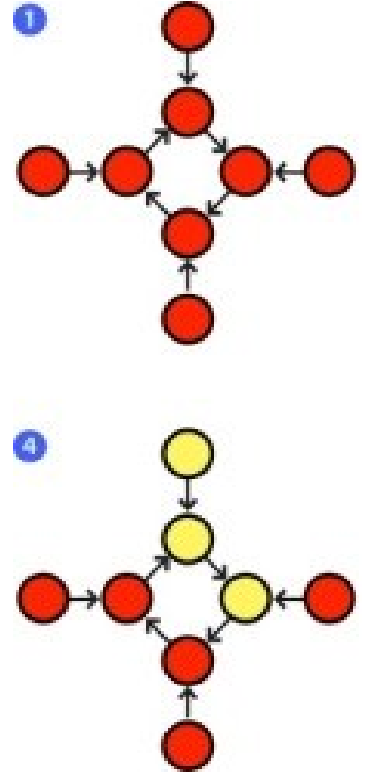
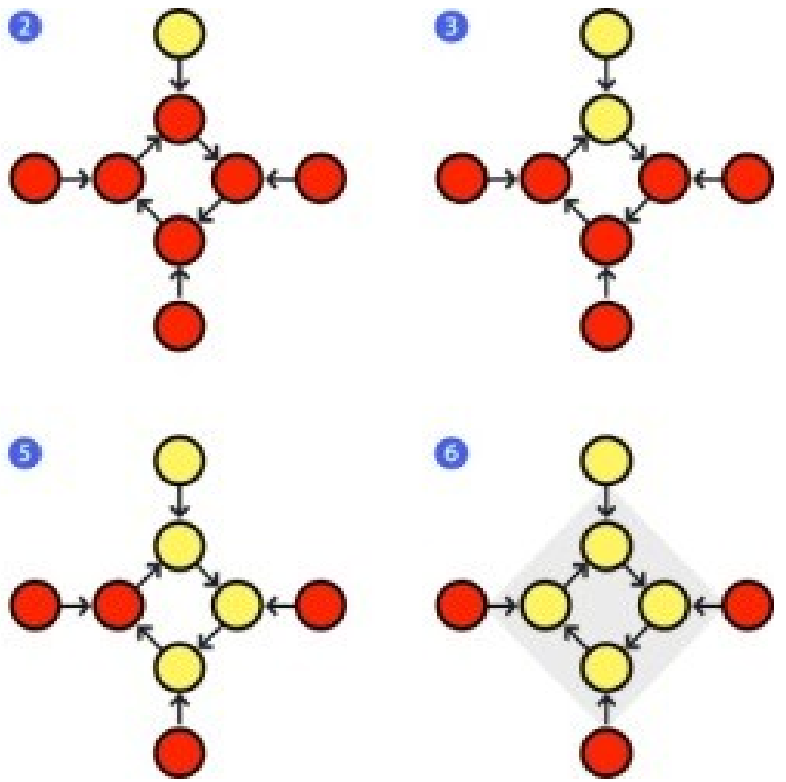

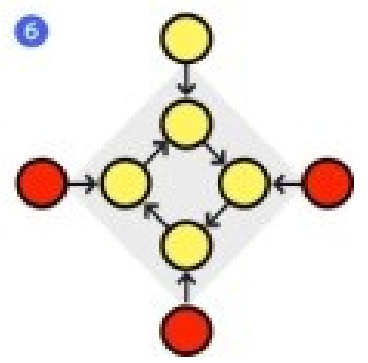

Figura 1. A rede Booleana acima, modificada de um exemplo de Kauffman (1991), mostra como um sistema pode se "solidificar" a ponto de impossibilitar a emergência de variações e comportamentos complexos. Elementos vermelhos estão desligados. Após um dos elementos ser ligado (amarelo), dada a estrutura da rede e a função Booleana envolvida, o sistema se congela em uma configuração que não muda com o tempo.

A auto-organização, segundo Kauffman (1991, 1993), é um fenômeno que ocorre na transição de fase entre um estado estável e um caótico. Nessa região de transição de fase, em que comportamentos complexos podem ocorrer, ordenados o suficiente para assegurar tanto estabilidade quanto flexibilidade, apareceriam propriedades emergentes como a vida e, consequentemente, a evolução biológica. Na fase líquida emerge o "todo maior que a soma das partes", o que torna possível a exploração de novos padrões, imprevisíveis simplesmente a partir da análise dos componentes iniciais do sistema.

Muito mais do que um conceito matemático, a auto-organização é um fenômeno natural. No contexto biológico, em sistemas suficientemente complexos, auto-organização e seleção serão processos relacionados, trabalhando em paralelo para produzir organização e 
fenômenos macroscópicos. Essa relação entre auto-organização e seleção natural pode fornecer, segundo Depew \& Weber (1995), indicativos para uma nova síntese evolutiva. Quando Darwin sugeriu, em carta de 1871 endereçada a seu colega botânico Joseph Hooker, que a primeira forma de vida poderia ter surgido em algum tipo de pequeno corpo d'água quente com todos os tipos de amônia e sais fosfóricos dissolvidos e capazes de passar por mudanças complexas, ele assumiu a existência de uma organização prévia que, uma vez estabelecida sua identidade biológica, seria capaz de variar e ser selecionada. Está implícito no raciocínio darwiniano um princípio gerador de ordem (no caso, a autoorganização) como condição sine qua non para que a seleção natural atue.

A relação entre auto-organização e seleção natural pode ser compreendida a partir de três perspectivas (Depew \& Weber, 1995): (1) a seleção natural dirige a evolução; (2) a autoorganização dirige a evolução; ou (3) a seleção natural e a auto-organização são dois aspectos importantes e complementares da evolução. Desconsiderar a auto-organização não nos permite compreender o cenário pré-biótico, no qual, por definição, não poderia existir seleção natural, que é a medida da reprodução diferencial dos organismos. Renegar o papel do mecanismo evolutivo da seleção natural é desconsiderar mais de uma centena de anos de evidências sobre o seu papel na evolução (Gould, 2002). Depew \& Weber (1995) defendem que a seleção natural surgiu com a própria vida, a partir da dinâmica estocástica e auto-organizacional, assumindo, a partir daí, o papel de conferir às populações a maximização da sua aptidão. Isso significa que processos estocásticos, seletivos e de autoorganização são entrelaçados na evolução dos sistemas vivos, em conexões tão estreitas que o próprio conceito de seleção natural relaciona-se intrinsicamente com o acaso e a auto-organização. A seleção natural, nesse ponto de vista, não possuiria a capacidade de gerar variação ou de produzir ordem, já que atuaria sobre uma variabilidade previamente auto-organizada.

Depew e Weber (1995) propõem que a origem da vida foi um processo seletivo de ciclos de utilização e dissipação de energia. Os sistemas capazes de criar ciclos mais efetivos que seus competidores predominariam. Conjuntos autocatalíticos, na terminologia de Kauffman (1991, 1993), seriam favorecidos. Assim, antes da seleção do reprodutivamente mais eficaz (seleção biológica), teria havido seleção do estruturalmente estável (seleção física) e do quimicamente eficiente (seleção química). Como corolário, a seleção natural seria um processo emergente surgido a partir de sistemas dissipativos fora do equilíbrio termodinâmico, com habilidade de variar e reter informação. Estas estruturas dissipativas (Nicolis \& Prigogine, 1977) consistem de processos onde flutuações dão lugar a configurações macroscópicas (padrões espaço-temporais) que se estabilizam através do fluxo de energia que atravessa o sistema. A auto-organização aqui se entende então como uma sucessão de instabilidades e flutuações nas quais as estruturas dissipativas, cada vez que alcançam um ponto de instabilidade, evoluem de forma espontânea até novas estruturas e organizações. A evolução da matéria é, portanto, uma sucessão de flutuações em que estruturas dissipativas provocam emergência de novas ordens e novos níveis hierárquicos de complexidade.

O estado de não-equilíbrio é uma condição necessária, mas não suficiente para a dinâmica biológica organizada (Moreno \& Ruiz-Mirazo, 2009). Furacões, tornados e reações auto-catalíticas são exemplos de estruturas dissipativas longe do equilíbrio com organização coerente. A principal diferença entre estruturas dissipativas formadas espontaneamente e sistemas autônomos vivos reside na relação interior/exterior. No primeiro caso, as restrições exigidas são externas ao sistema, enquanto em sistemas autônomos vivos essas restrições moldam os processos metabólicos, são endógenas e criadas internamente pelo sistema. 
Assim, a autonomia traz a noção de sistemas que, de forma recursiva, constroem as restrições que os constituem, capazes de gerenciar ativamente a troca de matéria e energia com seu ambiente. Ainda, todos os sistemas biológicos apresentam diferenciação e fechamento organizacional, além de uma função (Moreno \& Ruiz-Mirazo, 2009). Nenhum sistema natural não-biológico cumpre todas essas condições ao mesmo tempo.

A diferenciação organizacional seria um requisito para atribuições funcionais no nível biológico, pois ela implica que o próprio sistema gere estruturas distintas que contribuem para sua automanutenção - dessa forma, as restrições não seriam apenas externas ao sistema. O fechamento organizacional é uma propriedade que designa a mútua dependência entre restrições do sistema, cada uma das quais exercendo uma contribuição específica e distinta à manutenção das condições de contorno que permitem a existência do conjunto vivo. Essa mútua dependência entre restrições permite aos diferentes componentes do sistema realizar a automanutenção de forma coletiva. As funções biológicas estariam relacionadas com um tipo específico de organização físico-química característica do que é vivo. A vida é, portanto, um tipo distinto de organização em que o aspecto (auto) organizativo é dado por seu caráter autônomo que constitui e mantém a si mesmo.

Há aqui um duplo nível explicativo: o nível dos padrões profundos (introduzido pelo componente auto-organizativo) que conduzem a evolução, e o nível das reconstruções particulares e potencialmente únicas (seleção natural). Os dois planos são independentes em termos metodológicos e conceituais, porém complementares: a própria distinção entre leis e narrativas é repensada e a relação entre seleção e auto-organização torna-se mais dinâmica.

É certo que os episódios isolados podem ser contingentes, e ao se repetir a fita da vida na Terra, obteríamos sequências cada vez mais distintas (Gould, 2002). No entanto, as "soluções biológicas" poderiam se reagrupar em torno de atratores, a partir dos quais seria possível a repetição de padrões morfológicos e funcionais regulares, ainda que o mundo biológico não fosse exatamente igual. Sistemas vivos completamente diferentes teriam, assim, capacidades funcionais análogas. Essa noção de função está associada à autoorganização: novos modos de funcionamento das partes constituintes do sistema vivo estabeleceriam novas relações de funcionalidade desse sistema.

O cenário supracitado pode ser visto como um tipo de darwinismo auto-organizativo, que permite aproximar a fronteira entre o inanimado e a ordem biológica. Um possível darwinismo estendido ilumina esse tipo de aproximação à medida que permite às leis da física e às idiossincrasias da biologia se encontrarem um espaço conceitual apropriado.

\section{Mundo pré-biótico e emergência}

Para Bada \& Lazcano (2002), existem duas visões principais sobre como se deu a transição dos componentes orgânicos abióticos para moléculas autônomas auto-replicantes capazes de evoluir por seleção natural. A primeira é a corrente heterotrófica ou da sopa pré-biótica, que defende a impossibilidade de vida sem uma molécula informacional (tais como DNA, RNA, PNA, t-RNA); a partir da polimerização de componentes orgânicos dos oceanos primitivos seriam produzidas macromoléculas complexas, que por acaso começariam a catalisar sua própria replicação. A segunda, corrente autotrófica ou metabólica, diz que a presença de um sistema informacional não teria sido necessária para o surgimento da vida. Os organismos primitivos seriam caracterizados por uma série de 
reações autossustentadas, que aumentaria sua complexidade com o tempo. baseadas em compostos orgânicos simples.

Bada \& Lazcano (2002) enfatizam que a vida de base química autocatalítica metabólica não poderia ter evoluído na ausência de um mecanismo de replicação genética que pudesse assegurar tanto a estabilidade quanto a diversificação dos seus componentes. Sem mecanismos hereditários, as cadeias de reação autotróficas não deixariam descendentes capazes de garantir a manutenção do processo. No entanto, a proposta dos conjuntos autocatalíticos de Kauffman $(1991,1993)$ insere-se na linha autotrófica ou metabólica e enfatiza a possibilidade de surgir espontaneamente um sistema biológico ordenado capaz de fazer sua própria manutenção e replicação mesmo sem a presença de maquinaria genética - o que contraria a imagem do material genético como agente central de toda forma de vida. Tal cenário aponta para a existência pretérita de moléculas interagindo até o estabelecimento de um conjunto catalítico "líquido" e com potencial evolutivo. Quando um número suficientemente grande de reações é catalisado em um sistema de reações químicas, uma vasta rede se cristaliza rapidamente, de tal modo que ela resulta em um sistema auto-catalítico e autossustentado. Dessa maneira, um mínimo de diversidade de moléculas e de interconexões entre elas seria imprescindível para o estabelecimento de uma rede auto-catalítica, ou então o sistema não passaria de uma sopa inerte de reações que transcorreriam tão lentamente que seriam incapazes de iniciar sua evolução (Kauffman, 1993).

Nesse ínterim, torna-se fundamental compreender o fenômeno da emergência nos sistemas complexos (Moreno \& Ruiz-Mirazo, 2009). A origem da vida pode ser compreendida como o resultado de propriedades coletivas emergentes a partir de uma mistura de polímeros catalíticos organizados em redes complexas que se auto-mantém e autorregulam. Assim, as propriedades replicantes de moléculas como DNA e RNA seriam essenciais para o tipo de vida que conhecemos, não para a vida em si. A ordem fundamental seria mais profunda, baseada na auto-organização, e as rotas para a vida mais amplas (Kauffman, 1991, 1993). A corrente autotrófica privilegia uma definição mais geral de vida, que englobe qualquer bioquímica alternativa, e parece promissora em uma perspectiva universal da biologia, não restrita aquilo que conhecemos no planeta Terra.

Uma característica dos sistemas emergentes é a impossibilidade de predição de seus estados futuros, já que a extrema sensibilidade às condições iniciais não permite fazer qualquer antecipação (Depew \& Weber, 1995). Das interações entre os componentes emergem comportamentos completamente novos e irredutíveis às suas condições originais. Esse é o conceito de emergência ontológica, segundo o qual a natureza dos sistemas dinâmicos é a de portarem níveis superiores com capacidades e características não presentes nos seus componentes (Emmeche et al., 1997). Como citado anteriormente, uma definição satisfatória de vida deve ser capaz de tratá-la em sua totalidade como um fenômeno cósmico. Talvez seja a emergência ontológica a característica definidora dos sistemas vivos em qualquer parte do universo: criando uma identidade própria do sistema, identidade essa não presente no mundo não-vivo, o sistema global vai mudando as propriedades das suas partes. Resulta-se aí que um todo não corresponde apenas ao somatório das propriedades dos seus constituintes.

A relação dinâmica entre as leis naturais e as contingências é o fio condutor para uma filosofia universal da biologia. Uma história particular nunca se repete, mas as regularidades emergem no decorrer do tempo e nesse ponto deve-se buscar tais regularidades e extrapolá-las para algum grau de generalidade. O estatuto epistemológico da biologia deve aceitar que qualquer cenário evolutivo (por exemplo, adaptações biológicas) tenha como 
pano de fundo padrões gerais que dizem respeito à ordem biológica no seu sentido mais fundamental.

Sob esse cenário, estudando os sistemas auto-organizados do ponto de vista de sua autonomia, pode-se descobrir os princípios de emergência, que se tornam instrumento importante no estudo da dinâmica das novidades qualitativas. A construção de modelos como os de Kauffman (1993) mostra que, a partir de unidades interagentes e de regras simples, é possível reproduzir comportamentos coletivos e emergentes. Estar vivo é uma questão de organização. O novo darwinismo universal deve ser construído nesse nível de abstração. As generalizações vão ser encontradas em um intermediário sistêmico integrativo, no qual reside a possibilidade de existência de um algoritmo biológico universal.

Considerar apenas a seleção natural de replicadores é insuficiente para fundamentar uma definição de vida como qualidade emergente. Na filosofia da biologia, antes consolidada em torno de um enfoque reducionista centrado na visão genecentrista e no adaptacionismo como critério fundamental (Gould \& Lewontin, 1979), começam a surgir alternativas pluralistas que refletem a necessidade de uma síntese estendida da evolução, que pode levar a um quadro conceitual para o desenvolvimento de uma biologia universal. A origem da ordem no universo e a emergência da organização biológica na Terra ou fora dela devem ser compreendidas à luz tanto da seleção natural como dos sistemas autoorganizativos. A busca por princípios biológicos universais, dentro de um corpo teórico unificador, resgata o pluralismo darwiniano (Darwin, 1859).

Portanto, à pergunta inicial sobre a capacidade de detectar se existe vida fora da Terra a partir de ferramentas conceituais e empíricas baseadas no Darwinismo Universal, a resposta é negativa, visto que a visão corrente, e.g., defendida por Dawkins (1983) e Darling (2007), é extremamente restritiva. Um novo darwinismo universal é necessário, baseado em uma visão estendida da teoria evolutiva, capaz de permitir o desenvolvimento de novos desenhos experimentais teórico-práticos, inferências que conectem de forma mais profunda a relação entre história, estrutura e função, e predições com base em generalizações e regularidades biológicas (Winther, 2008).

\section{Um novo Darwinismo Universal}

Para compreender a natureza da vida é necessário transcender definições baseadas no darwinismo ortodoxo, pautado pela supremacia da seleção natural (Gould \& Lewontin, 1979), e reconhecer os limites impostos pelas leis da física e da química tanto quanto pela contingência histórica característica dos sistemas biológicos. O darwinismo universal (Dawkins, 1983), que encontra eco no discurso adaptacionista típico de certas vertentes da biologia evolutiva, só terá de fato universalidade se incluir, além da importância da seleção de variedades pré-existentes, também o conceito de emergência ontológica: entidades biológicas têm capacidades que não estão presentes em entidades físicas pré-biológicas (Emmeche et al., 1997).

A vida seria, então, um tipo distinto de organização da matéria? É provável que sim. A biologia, portanto, é tão universal quanto a física e a química, e corresponde a algo maior do que a simples soma dos seus termos físico-químicos. É injustificada, dessa forma, qualquer tentativa de reduzir os sistemas biológicos apenas à física. A vida se prefigura no limite entre sistemas completamente caóticos e os rigidamente ordenados. Entender a sua natureza subjacente a partir de um conceito estendido de darwinismo universal nos 
aproxima da possibilidade de definir vida como um tipo natural, definição essa válida aqui e em qualquer outro lugar do cosmo.

Pode-se preconizar, com isso, uma nova etapa para a biologia, com a incorporação cada vez maior de princípios da física, da química e da filosofia, que nos permitirá ter a visão do todo e não somente de suas partes (Winther, 2008; Santos \& Alabi, 2013). Para esse novo modo de pensar o mundo biológico, a repetição reiterada de padrões seria fruto de "leis" do organismo, baseadas na auto-organização e na emergência, e a vida não seria mais considerada produto meramente do acaso. Se os organismos forem expressões de leis naturais baseada não em acidentes improváveis, mas da ordem natural esperada, nós estaríamos "em casa no universo" (Kauffman, 1995). A seleção natural sem autoorganização é cega, a auto-organização sem seleção natural é vazia. Faz-se necessário estudar como as duas se relacionam para explicar a origem a diversificação orgânica, no que chamamos aqui de um darwinismo estendido, que leve em conta o componente autoorganizativo fundamental para o fenômeno da vida no universo. Exemplos que caminham nessa direção têm sido aventados para explicar desde o comportamento social de formigas (Miramontes, 2007) até expressões mínimas da vida (Ruiz-Mirazo, 2008) e parecem um bom ponto de partida onde leis da física e da biologia se entrelaçam.

Tal darwinismo estendido comporta um espaço conceitual mais abrangente, abarcando uma rede integrada de conceitos que caminha para a definição do grau de universalidade e autonomia requeridos para uma compreensão mais geral da vida (seja na Terra ou fora dela). O darwinismo estendido em seu espaço conceitual de múltiplas dimensões é uma ferramenta que permite a aproximação entre os vértices seletivo, estrutural e funcional, pois é um conjunto integrado que permite localizar generalizações biológicas (a despeito da historicidade e da contingência da vida) que tem sido a causa do aparecimento e da evolução das formas dos seres vivos no nosso planeta. Ainda que não haja uma definição universal de vida, é possível entendê-la observando todos os processos e padrões que os organismos constituem e dos quais fazem parte. A partir daí, pode-se expandir a questão para outras partes do universo, ao nos perguntarmos se a evolução se repete também em qualquer lugar fora da Terra e em que sentido a biologia pode ser considerada universal.

A ciência só é feita com um bom quadro teórico de fundo. Devemos assegurá-lo a todo o momento, principalmente em áreas que cruzam novos espaços. Esse é tanto o caso dos componentes na teoria da evolução, quanto de conceitos mais amplos como vida, que não pertencem somente a um programa de pesquisa específico. É certo que não sabemos se estamos sozinhos no Universo: a vida pode ser uma propriedade inerente à matéria, mas talvez tudo não passe de uma confluência de eventos única e sem paralelos em nenhum planeta. Entender como surgem as biosferas e como elas evoluem é prestar um tributo à ideia de que alguns dos aspectos aparentemente mais banais da natureza são os mais inescrutáveis e os mais maravilhosos.

\section{Agradecimentos}

Os autores agradecem a Jerzy Brzozowski (Universidade Federal da Fronteira Sul) e a Renato Kinouchi (Universidade Federal do $A B C$ ) pelos comentários em uma versão anterior desse manuscrito, e ao IAS-Research Investigação em Informação e Sistemas Autônomos, da Universidad del Pais Basco/Euskal Herriko Unibertsitatea, em especial a Alvaro Moreno e Kepa Ruiz-Mirazo pela discussões sobre auto-organização. O trabalho foi financiado pela Fundação Universidade Federal do ABC (Santo André/SP), pela CAPES e pelo CNPq. 


\section{Referências}

BADA, J. L. \& LAZCANO, A. Some like it hot, but not the first biomolecules. Science, v. 296, n. 5575, p. 1982-1983, 2002.

BENNER, S. A. Defining life. Astrobiology, v. 10, n. 10, p. 1021-1030, 2010.

CLELAND, C. E. \& CHYBA, C. F. Defining 'life'. Origins of Life and Evolution of the Biosphere, v. 32, n. 4, p. 387-393, 2002.

DARLING, D. Life Everywhere: The Maverick Science of Astrobiology. New York: Basic Books, 2007.

DARWIN, C. On the origin of species, or the preservation of favoured races in the struggle for life. London: John Murray, 1859.

DAVIES, P. C., BENNER, S. A., CLELAND, C. E., LINEWEAVER, C. H., MCKAY, C. P. \& WOLFE-SIMON, F. Signatures of a shadow biosphere. Astrobiology, v. 9, n. 2, 241-249, 2009.

DAWKINS, R. Universal Darwinism. In: BENDALL, D. S. (ed.) Evolution from molecules to man. Cambridge: Cambridge University Press, p. 403-425, 1983.

WEBER, B. H. \& DEPEW, D. J. Natural selection and self-organization. Biology and Philosophy, v. 11, n. 1, p. 33-65, 1996.

EL-HANI, C. N. Uma ciência da organização viva: organicismo, emergentismo e ensino de biologia. In: SILVA FILHO, Waldomiro et al. (Orgs.). Epistemologia e ensino de ciências. Salvador: Arcádia, p. 199242, 2002.

EL-HANI, C. N. \& EMMECHE, C. On some Theoretical grounds for an organism-centered biology: property emergence, supervenience and downward causation. Theory in Biosciences, v. 119, p. 234$275,2000$.

EMMECHE, C.; KØPPE, S. \& STJERNFELT, F. Explaining emergence: towards an ontology of levels. Journal for General Philosophy of Science, v. 28, p. 83-119, 1997.

GOULD, S. J. The structure of evolutionary theory. Cambridge: Harvard University Press, 2002.

GOULD, S.J. \& LEWONTIN, R. The Spandrels of San Marco and the Panglossian paradigm: a critique of the adaptationist programme. Proceedings of the Royal Society of London B., v. 205, p. 581-598, 1979.

KAUFFMAN, S. A. Antichaos and adaptation. Scientific American, v. 265, n. 2, p. 78-84, 1991.

KAUFFMAN, S. A. The origins of order: Self organization and selection in evolution. Oxford: Oxford University Press, USA, 1993.

KAUFFMAN, S. A. At home in the universe: The search for the laws of self-organization and complexity. Oxford: Oxford University Press, 1995.

KAUFFMAN, S. A. Prolegomenon to a general biology. Annals of the New York Academy of Sciences, v. 935, n. 1, p. 18-36, 2001.

KAUFFMAN, S. A. Molecular autonomous agents. Philosophical Transactions of the Royal Society of London. Series A: Mathematical, Physical and Engineering Sciences, v. 361, n. 1807, p. 1089-1099, 2003.

KAUFFMAN, S. A. Prolegomenon to patterns in evolution. BioSystems, v. 123, p. 3-8, 2014.

LUISI, P. L. About various definitions of life. Origins of Life and Evolution of the Biosphere, v. 28, n. 46, p. 613-622, 1998. 
MIRAMONTES, O. Complexity and behaviour in Leptothorax ants. Cidade do Mexico: CopIt ArXives, 2007.

MORENO, A. \& RUIZ-MIRAZO, K. The problem of the emergence of functional diversity in prebiotic evolution. Biology \& Philosophy, v. 24, n. 5, p. 585-605, 2009.

NICOLIS, G. \& PRIGOGINE, I. Self-organization in nonequilibrium chemical systems. Hoboken: Wiley, 1977.

RUIZ-MIRAZO, K.; ETXEBERRIA, A.; MORENO, A. \& IBÁÑEZ, J. Organisms and their place in biology. Theory in biosciences, v. 119, n. 3, 209-233, 2000

RUIZ-MIRAZO, K. \& MORENO, A. Basic autonomy as a fundamental step in the synthesis of life. Artificial Life, v. 10, n. 3, p. 235-259, 2004.

RUIZ-MIRAZO, K.; UMEREZ, J. \& MORENO, A. Enabling conditions for 'open-ended evolution'. Biology \& Philosophy, v. 23, n. 1, p. 67-85, 2008.

RUIZ-MIRAZO, K.; PERETÓ, J. \& MORENO, A. A universal definition of life: autonomy and open-ended evolution. Origins of life and evolution of the biosphere, v. 34, n. 3, p. 323-46, 2004.

RUIZ-MIRAZO, K. Self-organization. In: DUBITZKY, W.; WOLKENHAUER, O.; YOKOTA, H. \& CHO, K.-H. (Eds.) Encyclopedia of Systems Biology. New York: Springer, p. 1915-1919, 2013.

SANTOS, C. M. D. \& ALABI, L. P. Todo biólogo é um pouco astrobiólogo. Ciência Hoje, v. 302, p. 5657, 2013.

WINTHER, R. G. Systemic Darwinism. Proceedings of the National Academy of Sciences of the United States of America, v. 105, n. 33, p. 11833-11838, 2008. 